\title{
Two-Dimensional Metalloporphyrinic Framework Nanosheets-Based Dual-Mechanism-Driven Ratiometric Electrochemiluminescent Biosensing of Protein Kinase Activity
}

Guangyao Zhang, ${ }^{* \dagger}$ Mengjie Li,${ }^{\dagger}$ Kun $\mathrm{Yu},{ }^{\dagger}$ Huining Chai, ${ }^{*}$, Shenghao Xu, ${ }^{\S}$ Tailin Xu, ${ }^{\#}$ Lijun Qu, ${ }^{\dagger}$ and Xueji Zhang*,†,\#

${ }^{\dagger}$ Qingdao Center for Intelligent and Wearable Engineering, Research Center for Intelligent and Wearable Technology, College of Textiles and Clothing, State Key Laboratory of Bio-Fibers and Eco-Textiles, Qingdao University, Qingdao 266071, China

\$School of Environmental and Municipal Engineering, Qingdao University of Technology, Qingdao 266033, China

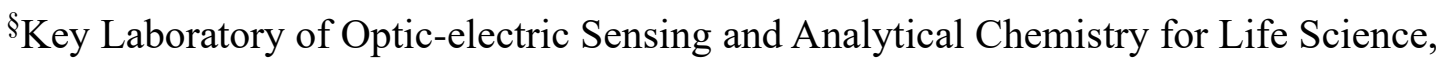
MOE, Qingdao University of Science and Technology, Qingdao 266042, China

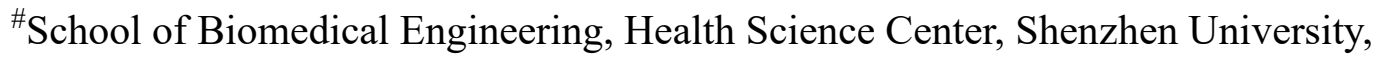
Shenzhen 518060, China

\section{${ }^{*}$ Corresponding Author}

*E-mail: gyzhang@qdu.edu.cn; chaihuining@qut.edu.cn; zhangxueji@szu.edu.cn.

Fax: $+86-532-85953358$ 
Table of Contents

1. Materials and Apparatus

\section{Supplementary Schemes and Figures}

\section{Supplementary Table}

\section{Reagents and Materials}

Cupric nitrate trihydrate $\left(\mathrm{Cu}\left(\mathrm{NO}_{3}\right)_{2} \cdot 3 \mathrm{H}_{2} \mathrm{O}\right)$, benzoic acid, protein kinase A (PKA; catalytic subunit from bovine heart), polyvinylpyrrolidone (PVP, $\mathrm{M}_{\mathrm{w}}=40,000 \mathrm{~g} / \mathrm{mol}$ ), adenosine $5^{\prime}$-[ $\gamma$-thio] triphosphate tetra-lithium salt (ATP-SH), ellagic acid, $N$-(3-chlorophenyl)-6,7-dimethoxy-4-quinazolinamine (Tyrphostin AG1478), tetraoctylammonium bromide (TOAB), luminol, tris(hydroxymethyl) aminomethane (Tris) and $N$-(2-hydroxyethyl)piperazine- $N$ '-(2-ethanesulfonic acid) (HEPES) sodium salt were purchased from Sigma-Aldrich Chemical Co., Ltd (Shanghai, China). Oligohistidine-tags (His-tags) kemptide ( $\mathrm{H}_{6}$-kemptide, HHHHHHCLRRASLG) was obtained from GL Biochem (Shanghai, China). Gold nanoparticles (GNPs, <10 nm, $0.1 \mathrm{~g} \mathrm{~L}^{-1}$ ) were purchased from Jiangsu XFNANO Materials Tech. Co., Ltd (Nanjing, China). Meso-tetra(4-carboxyphenyl)porphyrin (TCPP), zinc(II) meso-tetra(4-carboxyphenyl) porphine (ZnTCPP) was procured from J\&K Chemical Ltd (Shanghai, China). HeLa (human cervical cancer cell) cell extracts were purchased from RayBiotech. All other reagents were of analytical grade and were used without further purification. Ultrapure water obtained from a Millipore water purification system $(\geq 18 \mathrm{M} \Omega$, Milli-Q, Millipore) was used to prepare the aqueous solutions.

\section{Apparatus}

Transmission electron microscopy (TEM) analysis was carried out using a digital transmission electron microscope (Hitachi HT7700 Exalens, Japan). The morphology 
of the as-synthesized nanomaterials was investigated with a XL-30E scanning electron microscope (SEM). UV-vis absorption spectra were obtained using a UV-3600 UV-vis-NIR spectrophotometer (Shimadzu Co. Kyoto, Japan). Photoluminescence (PL) spectra were recorded at room temperature in a quartz cuvette on a FLSP920 fluorescence system. Powder X-ray diffraction (PXRD) was recorded on a Bruker D8-Focus Bragg-Brentano X-ray Powder diffractometer equipped with a $\mathrm{Cu}$ sealed tube $(\lambda=1.54178 \AA)$ at $40 \mathrm{kV}$ and $40 \mathrm{~mA}$. Electrochemical impedance spectroscopy (EIS) measurements were carried out using an Autolab PGSTAT30 (Eco chemie, The Netherlands) controlled by NOVA 1.10 software. EIS measurements were performed in $0.1 \mathrm{M} \mathrm{KCl}$ containing $5 \mathrm{mM} \mathrm{Fe}(\mathrm{CN})_{6}^{3-/ 4-}$ redox couple (1:1 molar ratio). The amplitude of the applied sine wave potential was $5 \mathrm{mV}$. The impedance measurements were recorded at a bias potential of $290 \mathrm{mV}$ within the frequency range of $10 \mathrm{kHz}$ to $0.1 \mathrm{~Hz}$. ECL measurements were carried out on an MPI-E II multifunctional electrochemical and chemiluminescent analytical system (Xi'an Remex Analytical Instrument Co., Ltd, China) in which the emission window lays above the photomultiplier tube biased at $-800 \mathrm{~V}$. All ECL studies were performed with a conventional three electrode system. A modified glassy carbon electrode (GCE, $5 \mathrm{~mm}$ in diameter), an $\mathrm{Ag} / \mathrm{AgCl}$ electrode and a $\mathrm{Pt}$ wire electrode were used as working, reference and counter electrodes, respectively. 


\section{Supplementary Schemes and Figures}

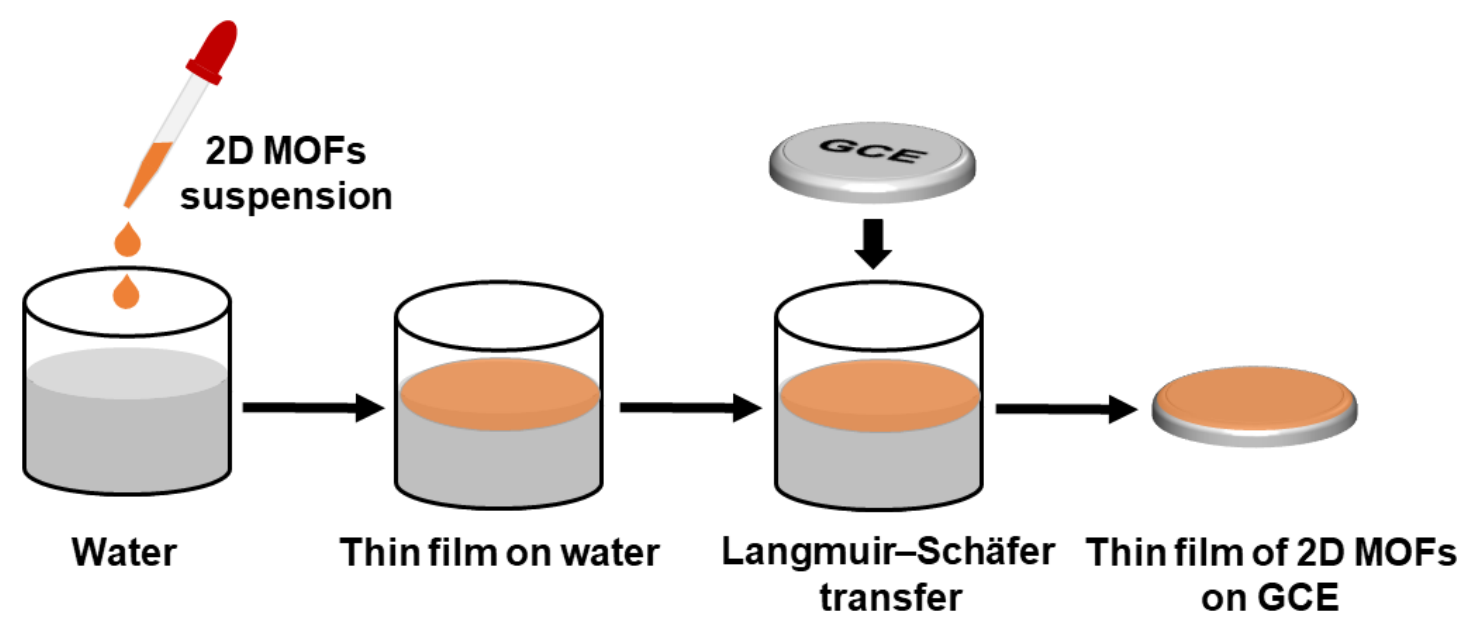

Scheme S1 Schematic illustration of the assembly process for preparation of 2D MOF nanosheets-based thin films. 


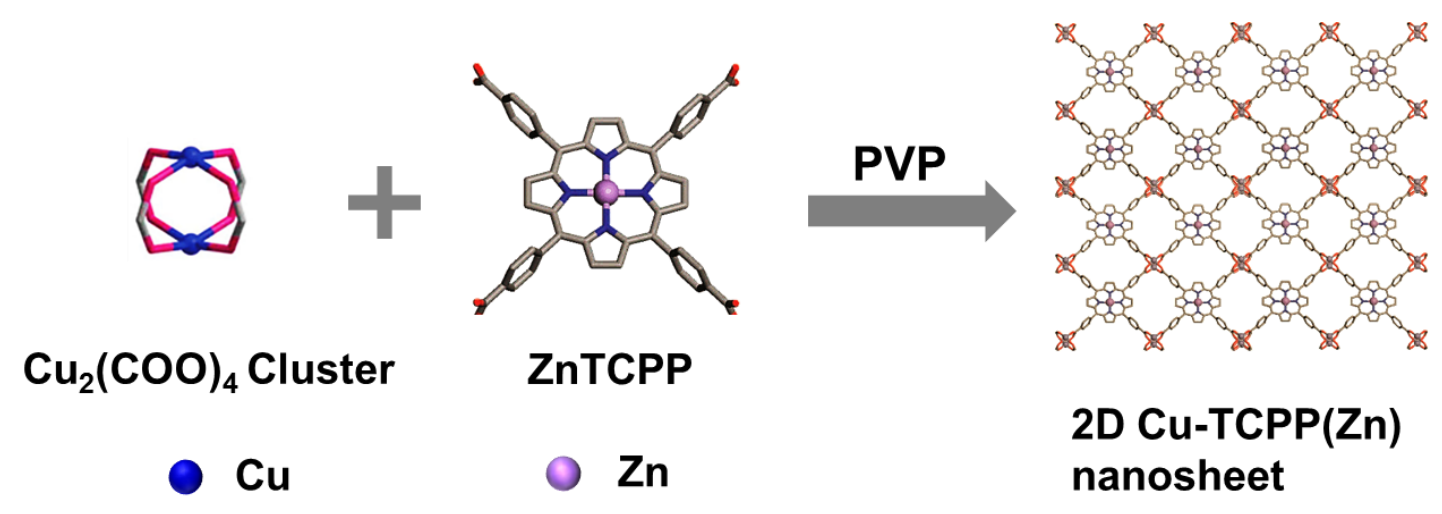

Scheme S2 Schematic representation of surfactant-assisted bottom-up synthesis of 2D $\mathrm{Cu}-\mathrm{TCPP}(\mathrm{Zn})$ nanosheets. 


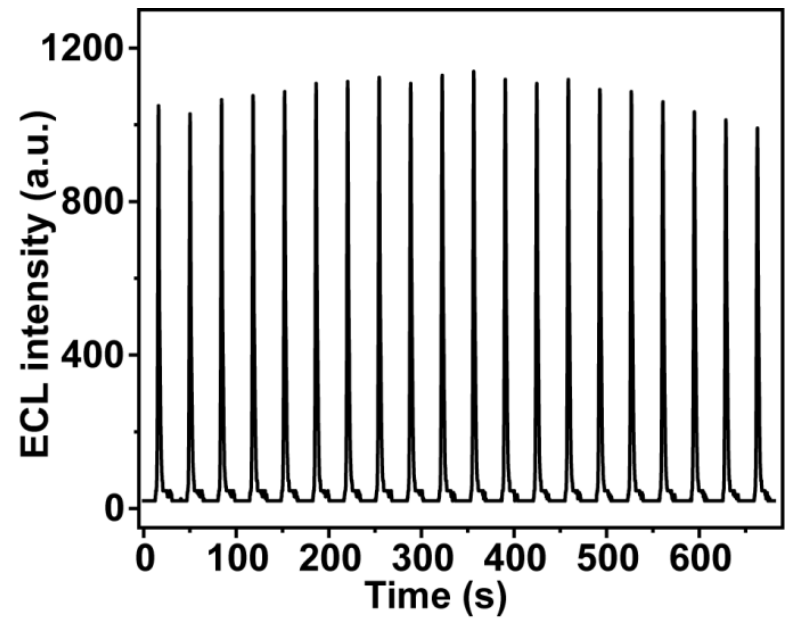

Figure S1 ECL-time response of GCE/2D Cu-TCPP(Zn)/TOAB recorded in $\mathrm{pH} 7.4$ HEPES solution during a continuous potential scan between -1.7 and $0 \mathrm{~V}$. Scan rate: $100 \mathrm{mV} \mathrm{s}^{-1}$. 

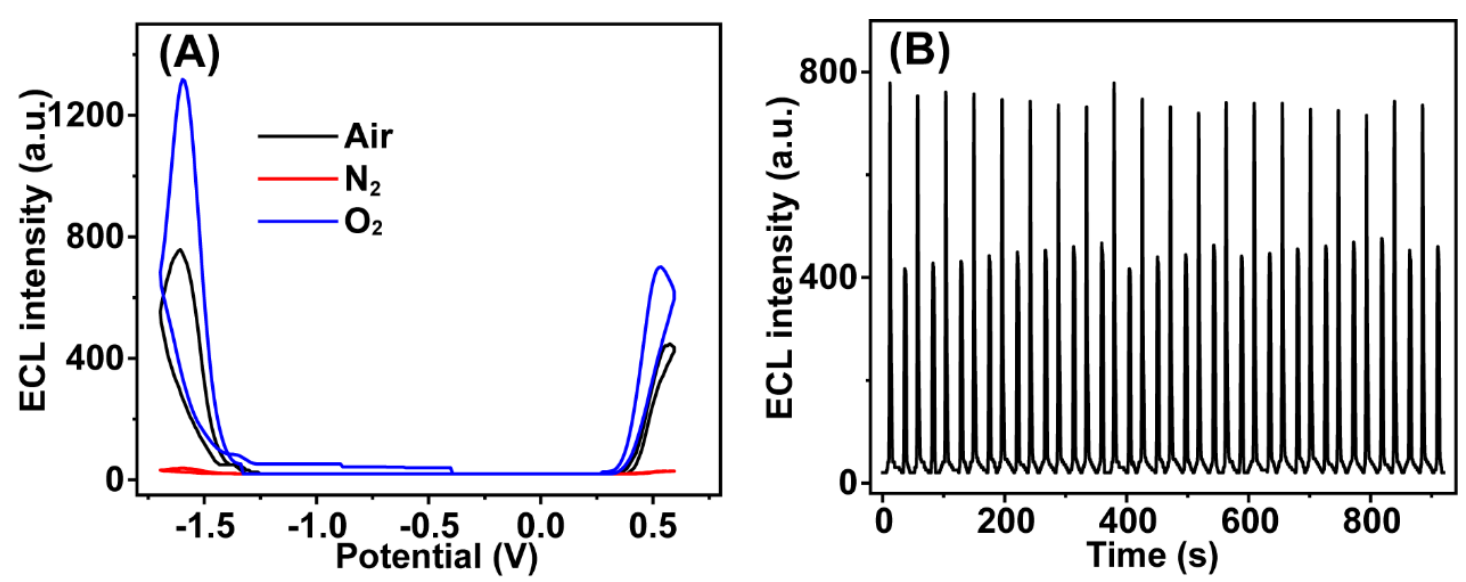

Figure S2 (A) ECL-potential curves of GCE/2D Cu-TCPP(Zn)/TOAB in the air-saturated, $\mathrm{N}_{2}$-saturated, and $\mathrm{O}_{2}$-saturated solution. (B) ECL-time response of GCE/2D Cu-TCPP(Zn)/TOAB recorded during a continuous potential scan. Condition: scan rate, $100 \mathrm{mV} \mathrm{s}^{-1}$; potential ranges, from $0 \mathrm{~V}$ to $-1.7 \mathrm{~V}$ to $0.6 \mathrm{~V}$ to $0 \mathrm{~V}$; HEPES, $10 \mathrm{mM}$, pH 7.4. 
Cathodic ECL process:

$\mathrm{O}_{2}+\mathrm{e}^{-} \rightarrow \mathrm{O}_{2}^{\cdot-}$

2D $\operatorname{MOF}\left(\mathrm{Zn}^{2+} \mathrm{TCPP}\right)+\mathrm{e}^{-} \rightarrow 2 \mathrm{D} \mathrm{MOF}\left(\mathrm{Zn}^{\circ+} \mathrm{TCPP}\right)$

2D MOF $\left(\mathrm{Zn}^{\bullet+} \mathrm{TCPP}\right)+\mathrm{e}^{-} \rightarrow 2 \mathrm{D} \operatorname{MOF}\left(\mathrm{Zn}^{\bullet+} \mathrm{TCPP}^{\bullet-}\right)$

$2 \mathrm{D} \mathrm{MOF}\left(\mathrm{Zn}^{\bullet+} \mathrm{TCPP}^{\bullet-}\right)+\mathrm{O}_{2}{ }^{--} \rightarrow 2 \mathrm{D} \mathrm{MOF}\left(\mathrm{Zn}^{\bullet+} \mathrm{TCPP}^{2-}\right)+{ }^{1} \mathrm{O}_{2}$

$2^{1} \mathrm{O}_{2} \rightarrow\left({ }^{1} \mathrm{O}_{2}\right)_{2}{ }^{*}$

$\left({ }^{1} \mathrm{O}_{2}\right){ }_{2}{ }^{*} \rightarrow 2^{3} \mathrm{O}_{2}+h v$

Anodic ECL process:

$\mathrm{LH}^{-}-\mathrm{e}^{-} \rightarrow \mathrm{L}^{--}+\mathrm{H}^{+}$

$\mathrm{L}^{--}+\mathrm{O}_{2}^{\cdot-} \rightarrow \mathrm{LO}_{2}{ }^{2-}$

$\mathrm{LO}_{2}{ }^{2-} \rightarrow \mathrm{AP}_{2}^{2-*}+\mathrm{N}_{2}$

$\mathrm{AP}_{2}{ }^{2-*} \rightarrow \mathrm{AP}_{2}{ }^{2-}+h v$

Equations S1-10 The possible mechanism of the 2D Cu-TCPP(Zn)-luminol competitive ECL system.

Based on the references ${ }^{1,2}$ and our experimental results, a possible mechanism of the 2D Cu-TCPP(Zn)-luminol competitive ECL system was proposed as shown in Equations S1-10. In the cathodic ECL process of potential scanning from 0 to $-1.7 \mathrm{~V}$, the dissolved $\mathrm{O}_{2}$ in the system was reduced by $2 \mathrm{D} \mathrm{MOF}$ to produce $\mathrm{O}_{2}{ }^{-}$. Immediately, the free radical anions of porphyrin $\left(\mathrm{Zn}^{\circ+} \mathrm{TCPP}^{\cdot-}\right)$ in the 2D MOF frameworks were formed after continuous electrochemical reduction. And, 2D $\mathrm{MOF}\left(\mathrm{Zn}^{\bullet+} \mathrm{TCPP}^{{ }^{-}}\right)$and $\mathrm{O}_{2}{ }^{\cdot-}$ reacted to generate ${ }^{1} \mathrm{O}_{2}$, producing a cathodic ECL response. In the anodic ECL process of potential scanning from 0 to $0.7 \mathrm{~V}$, large amounts of luminol anions $\left(\mathrm{LH}^{-}\right)$ were electrochemically oxidized into luminol anionic radicals $\left(\mathrm{L}^{-}\right)$. Then, the efficient reaction of $\mathrm{L}^{\cdot-}$ with electrogenerated $\mathrm{O}_{2}{ }^{\cdot-}$ produced the excited-state intermediates of 3 -aminophthalate anion $\left(\mathrm{AP}_{2}{ }^{2-*}\right)$, resulting in a significant anodic ECL emission. 

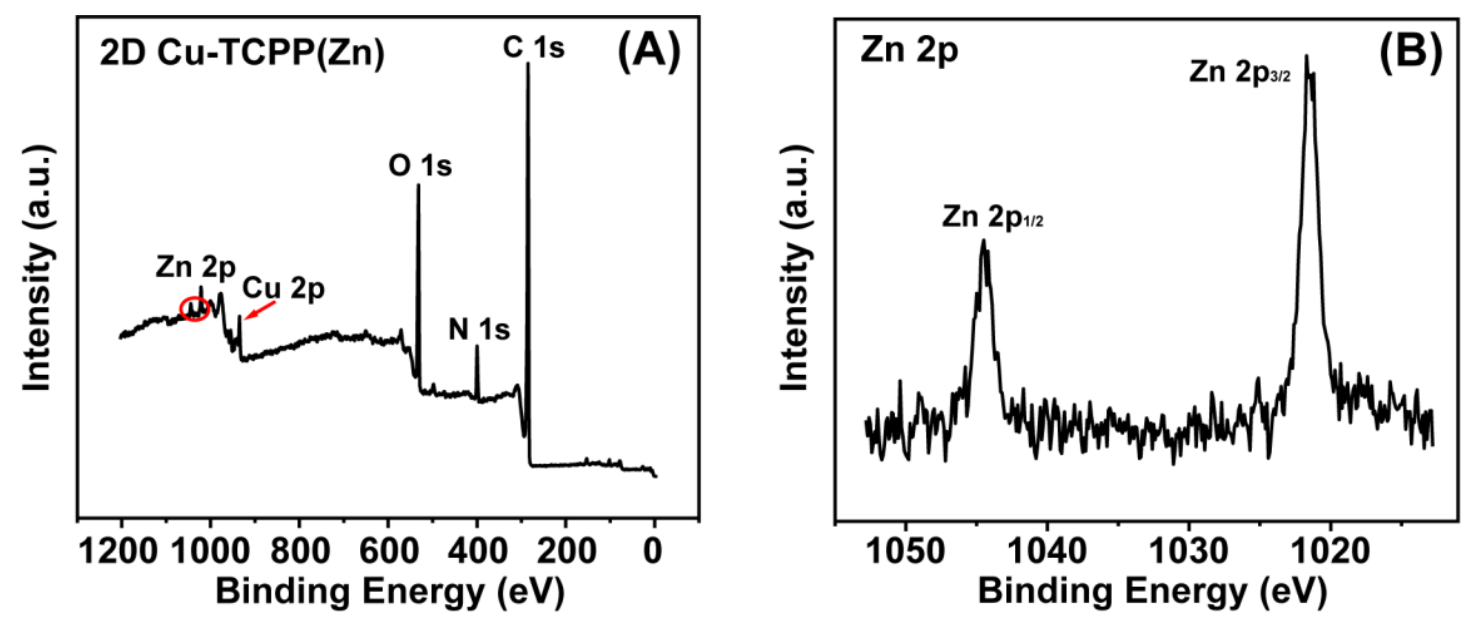

Figure S3 XPS survey scans (A) and the high-resolution XPS response of Zn 2p (B) core energy levels for 2D Cu-TCPP(Zn) and 2D Cu-TCPP(Zn)/H 6 -kemptide. 

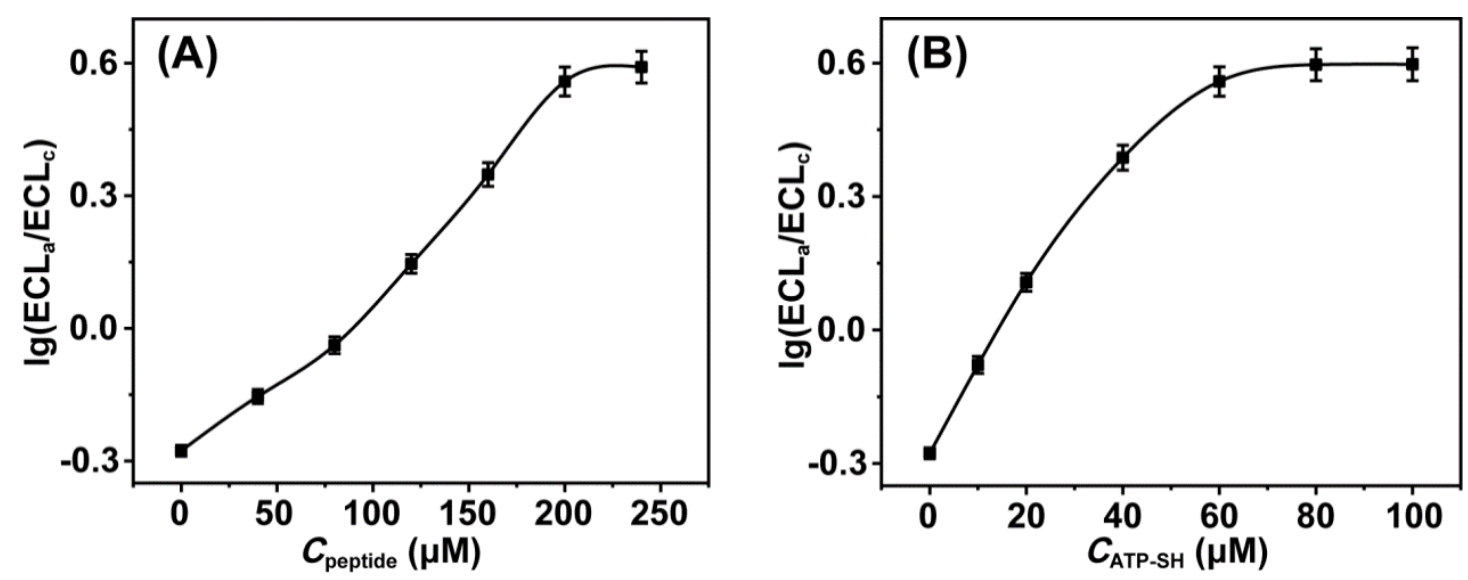

Figure S4 Effects of (A) peptide concentration and (B) ATP-SH concentration on the PKA biosensor.

Optimization of detection conditions. In order to obtain the best analytical performance of this ECL ratiometric biosensor, several experimental parameters including the concentration of peptide and the concentration of ATP-SH were optimized (Figure S4). As shown in Figure S4A, with increasing the peptide concentration from 0 to $200 \mu \mathrm{M}$, the cathodic ECL intensity increased, while the anodic ECL intensity from luminol decreased, respectively. Then both the two ECL signals reached a plateau when the concentration of peptide exceeded $250 \mu \mathrm{M}$. Therefore, to obtain high sensitivity, the optimum peptide concentration should be $200 \mu \mathrm{M}$. As shown in Figure S4B, the anodic ECL from luminol increased and the cathodic ECL decreased correspondingly with increasing the concentration of ATP-SH from 0 to $60 \mu \mathrm{M}$. However, a higher ATP-SH concentration $(>60 \mu \mathrm{M})$ was also unfavorable to the activity of PKA, leading to the decrease of the anodic ECL and the increase of the cathodic ECL. It is that peptide phosphorylation can be inhibited by high concentration of ATP derived from the competitive binding reaction between the peptide and ATP. Thus, $60 \mu \mathrm{M}$ ATP-SH was used in subsequent research. 


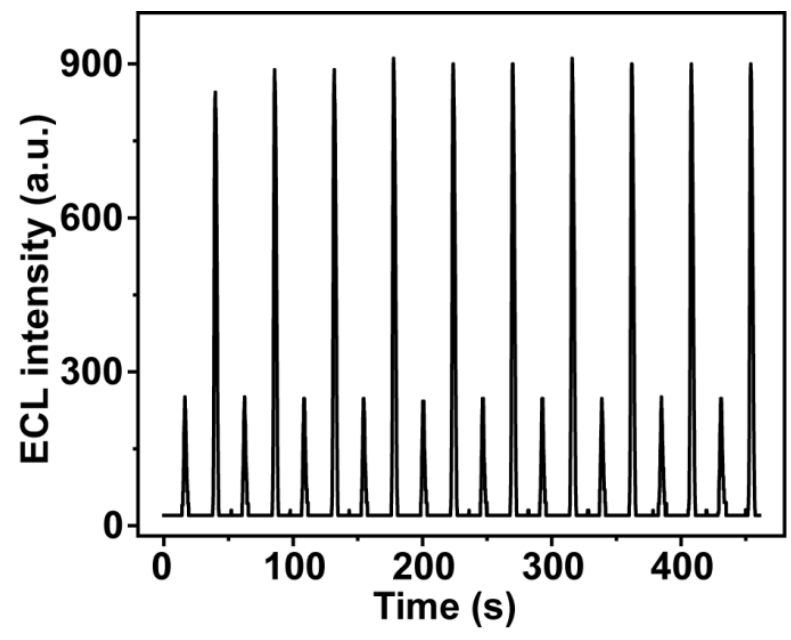

Figure S5 ECL-time response of the biosensor at PKA concentration of $0.1 \mathrm{U} \mathrm{mL}^{-1}$ under continuous potential scan with a scan rate of $100 \mathrm{mV} \mathrm{s}^{-1}$ in the $\mathrm{pH} 7.4$ HEPES solution containing $10 \mu \mathrm{M}$ luminol. 
Table S1. Comparison of different methods for PKA assay.

\begin{tabular}{|c|c|c|c|c|}
\hline Method & Key feature & Linear rang & LOD & Ref \\
\hline FRET $^{\mathrm{a}}$ & $\begin{array}{l}\text { Single quantum dot } \\
\text {-based nanosensor }\end{array}$ & $0.01-100 \mathrm{U} \mathrm{mL}^{-1}$ & $0.0093 \mathrm{U} \mathrm{mL}^{-1}$ & 3 \\
\hline $\mathrm{PEC}^{\mathrm{b}}$ & $\begin{array}{l}\text { Signal amplification } \\
\text { strategy }\end{array}$ & $0.1-100 \mathrm{U} \mathrm{mL}^{-1}$ & $0.048 \mathrm{U} \mathrm{mL}^{-1}$ & 4 \\
\hline $\mathrm{DPV}^{\mathrm{c}}$ & $\begin{array}{l}\text { Carboxypeptidase Y } \\
\text { assisted selective } \\
\text { peptide cleavage } \\
\text { reaction }\end{array}$ & $0.1-50 \mathrm{U} \mathrm{mL}^{-1}$ & $0.083 \mathrm{U} \mathrm{mL}^{-1}$ & 5 \\
\hline ECL & Au\&Pt@UiO-66 & $0.015-0.25 \mathrm{U} \mathrm{mL}^{-1}$ & $0.009 \mathrm{U} \mathrm{mL}^{-1}$ & 6 \\
\hline $\mathrm{PEC}^{\mathrm{b}}$ & {$\left[\mathrm{Ru}(\mathrm{bpy})_{3}\right]^{2+} @ \mathrm{UiO}-66$} & $0.005-0.0625 \mathrm{U} \mathrm{mL}^{-1}$ & $0.0049 \mathrm{U} \mathrm{mL}^{-1}$ & 7 \\
\hline ECL & $\begin{array}{l}\text { AuNPs-mediated } \\
\text { ratiometric method }\end{array}$ & $0.01-10 \mathrm{U} \mathrm{mL}^{-1}$ & $0.012 \mathrm{U} \mathrm{mL}^{-1}$ & 8 \\
\hline ECL & $\begin{array}{l}\text { Double-mechanism-in } \\
\text { duction ECL system }\end{array}$ & $0.005-5 \mathrm{U} \mathrm{mL}^{-1}$ & $0.0037 \mathrm{U} \mathrm{mL}^{-1}$ & $\begin{array}{l}\text { This } \\
\text { work }\end{array}$ \\
\hline
\end{tabular}

${ }^{\text {a}}$ FRET: Fluorescence resonance energy transfer; ${ }^{b} \mathrm{PEC}$ : Photoelectrochemistry; ${ }^{\mathrm{c} D P V}$ : Differential pulse voltammetry 
Table S2 PKA activity measured in $10 \times$ diluted HeLa cell lysates with the proposed biosensor $(n=3)$.

\begin{tabular}{ccccc}
\hline Samples & Add $\left(\mathrm{U} \mathrm{mL}^{-1}\right)$ & Found $\left(\mathrm{U} \mathrm{mL}^{-1}\right)$ & Recovery $(\%)$ & RSD (\%) \\
\hline 1 & 0.05 & 0.048 & 96 & 3.05 \\
2 & 0.1 & 0.106 & 106 & 3.26 \\
3 & 1 & 1.08 & 108 & 3.53 \\
\hline
\end{tabular}




\section{REFERENCES}

1. Zhang, G.; Chai, H.; Tian, M.; Zhu, S.; Qu, L.; Zhang, X., ZirconiumMetalloporphyrin Frameworks-Luminol Competitive Electrochemiluminescence for Ratiometric Detection of Polynucleotide Kinase Activity. Anal. Chem. 2020, 92(10), $7354-7362$.

2. Gu, W.; Wang, H.; Jiao, L.; Wu, Y.; Chen, Y.; Hu, L.; Gong, J.; Du, D.; Zhu, C., Single-Atom Iron Boosts Electrochemiluminescence. Angew. Chem., Int. Ed. 2020, 59(9), 3534-3538.

3. Wang, L.-j.; Yang, Y.; Zhang, C.-y., Phosphorylation-Directed Assembly of a Single Quantum Dot Based Nanosensor for Protein Kinase Assay. Anal. Chem. 2015, 87(9), 4696-4703.

4. Li, X.; Zhu, L.; Zhou, Y.; Yin, H.; Ai, S., Enhanced Photoelectrochemical Method for Sensitive Detection of Protein Kinase A Activity Using $\mathrm{TiO}_{2} / \mathrm{g}-\mathrm{C}_{3} \mathrm{~N}_{4}$, PAMAM Dendrimer, and Alkaline Phosphatase. Anal. Chem. 2017, 89(4), 2369-2376.

5. Liu, J.; Cheng, H.; He, D.; He, X.; Wang, K.; Liu, Q.; Zhao, S.; Yang, X., Label-Free Homogeneous Electrochemical Sensing Platform for Protein Kinase Assay Based on Carboxypeptidase Y-Assisted Peptide Cleavage and Vertically Ordered Mesoporous Silica Films. Anal. Chem. 2017, 89(17), 9062-9068.

6. Yan, Z.; Wang, F.; Deng, P.; Wang, Y.; Cai, K.; Chen, Y.; Wang, Z.; Liu, Y., Sensitive electrogenerated chemiluminescence biosensors for protein kinase activity analysis based on bimetallic catalysis signal amplification and recognition of $\mathrm{Au}$ and Pt loaded metal-organic frameworks nanocomposites. Biosens. Bioelectron. 2018, 109, 
$132-138$.

7. Wang, Z.; Yan, Z.; Wang, F.; Cai, J.; Guo, L.; Su, J.; Liu, Y., Highly sensitive photoelectrochemical biosensor for kinase activity detection and inhibition based on the surface defect recognition and multiple signal amplification of metal-organic frameworks. Biosens. Bioelectron.2017, 97, 107-114.

8. Zhao, H.-F.; Liang, R.-P.; Wang, J.-W.; Qiu, J.-D., A dual-potential electrochemiluminescence ratiometric approach based on graphene quantum dots and luminol for highly sensitive detection of protein kinase activity. Chem. Commun. 2015, 51(63), 12669-12672. 